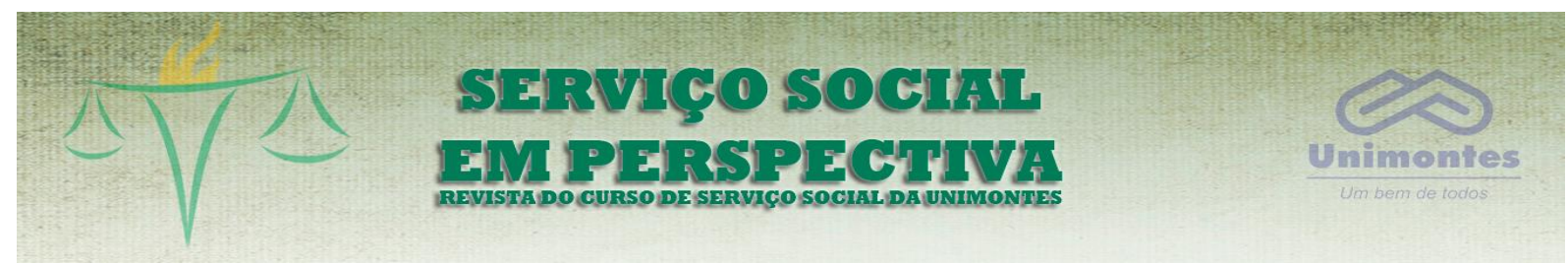

\title{
A CONJUNTURA DE UMA PANDEMIA E O QUE AINDA ESTÁ POR VIR - IMPACTOS E ESTRATÉGIAS POSSÍVEIS ${ }^{1}$
}

\section{THE CONJUNCTURE OF A PANDEMIC AND WHAT'S STILL TO COME - IMPACTS AND POSSIBLE STRATEGIES}

Resumo: O presente artigo foi construído a partir das reflexões apresentadas em uma live promovida pelo CRESS/6 ${ }^{\text {a }}$ Região - Seccional Monte Claros em parceria com a Unimotes, no dia 29 de maio de 2020. Desse modo, procura apresentar, inicialmente, alguns elementos que demonstram as características da atual ofensiva do capital, nos termos de uma crise estrutural. Esse primeiro movimento pretende situar a conjuntura macro-política, econômica e social em que se desenvolve o atual momento de pandemia provocada pela COVID-19. Em seguida, o artigo analisa algumas das principais tendências do atual governo brasileiro - governo Bolsonaro, destacando a necropolítica e o direcionamento genocida. E, por fim, propõe um debate acerca de algumas possibilidades táticas e estratégicas a serem construídas pelos os setores da esquerda, no Brasil. O capitalismo contemporâneo nos apresenta claros sinais de esgotamento. Portanto, esse momento requer organização e luta em prol da construção de uma nova sociedade para além do capital.

Palavras-chave: Crise estrutural do capital. Pandemia. Governo Bolsonaro. Esquerda brasileira.

Abstract: This article was built from the reflections presented in a live promoted by CRESS / 6th Region - Seccional Monte Claros in partnership with Unimotes, on May 29,2020 . Thus, it seeks to present, initially, some elements that they demonstrate the characteristics of the current capital offensive, in terms of a structural crisis. This

\footnotetext{
${ }^{1}$ Artigo construído a partir das reflexões apresentadas na live promovida pelo CRESS/6 ${ }^{\mathrm{a}}$ Região - Seccional Monte Claros em parceria com a Unimotes, no dia 29 de maio de 2020.

2 Assistente Social. Doutorado em Serviço Social pela Universidade Federal do Rio de Janeiro. Professora Adjunta na Faculdade de Serviço Social da Universidade Federal de Juiz de Fora. Integrante do Grupo de Estudos e Pesquisas dos Fundamentos do Serviço Social (GEPEFSS). Email: lugppaula@ gmail.com.
} 
first movement aims to situate the macro-political, economic and social situation in which the current pandemic moment caused by COVID-19 is developing. Then, the article analyzes some of the main trends of the current Brazilian government Bolsonaro government, highlighting necropolitics and genocidal direction. And, finally, it proposes a debate about some tactical and strategic possibilities to be built by the sectors of the left, in Brazil. Contemporary capitalism presents us with clear signs of exhaustion. Therefore, this moment requires organization and struggle for the construction of a new society beyond capital.

Keywords: Structural crisis of capital. Pandemic. Bolsonaro government. Brazilian left.

\section{INTRODUÇÃO}

A compreensão da realidade social, econômica e política do Brasil, no ano de 2020, tem desafiado até mesmo os grandes teóricos, experts no assunto. Isso porque se não bastasse a atual conjuntura de grave crise política no cenário nacional, o nosso país também vem sofrendo duramente com os impactos da pandemia mundial provocada pela COVID-19.

Com isso, a difícil tarefa de realizar uma análise de conjuntura torna-se um desfio ainda maior, nesse momento. Para o exercício dessa tarefa temos duas possibilidades, dois caminhos: o primeiro deles é colocar o nosso foco de análise no mar de lama e na aparente falta de direção do atual governo Bolsonaro - no entanto, esse caminho certamente nos possibilitará pouco alcance e nos apresentará apenas a superfície epidérmica das questões postas; o segundo caminho requer a ultrapassagem dessa cortina de fumaça, para que consigamos enxergar além de tudo o que diariamente nos distrai. Essa é a direção que nos possibilita fazer uma análise profunda e crítica do atual momento histórico, sem apartá-lo do processo que o concebeu.

Realizando a defesa da análise crítica da realidade, alicerçada no método materialista histórico dialético, optamos, nesse artigo, pelo segundo caminho.

Portanto, nossa tarefa será apresentar alguns elementos que demonstram as características da atual ofensiva do capital, nos termos de uma crise estrutural; em seguida analisar algumas tendências do atual governo brasileiro; e, por fim, propor o debate acerca de algumas possibilidades táticas e estratégicas para os setores da esquerda, no Brasil. 
Destacamos que as reflexões aqui apresentadas são expressão do acúmulo teórico-metodológico coletivo de setores de nossa sociedade que seguem atentos ao seu tempo histórico.

\section{CRISE ESTRUTURAL DO CAPITAL E SEU MOMENTO DE COLAPSO PANDÊMICO}

Em meio ao cenário devastador em que hoje vivemos, nesse primeiro quarto do século XXI, a pandemia provocada pela COVID-19, que assola todo o planeta, é apenas o elemento que escancara a perversidade do nosso tempo histórico.

O grande teórico marxista István Mészáros ${ }^{3}$, em uma palestra proferida em São Paulo, no ano de 2011, para o lançamento de dois livros, já nos alertava dizendo que se Rosa Luxemburgo escrevesse sua célebre frase "socialismo ou barbárie" nos dias atuais, a máxima mais adequada seria: "barbárie... se tivermos sorte".

Recorrendo ao próprio autor, é Mészáros (2009) que nos traz importantes reflexões para compreendermos a crise estrutural do capital. O autor apresenta em sua obra "A crise estrutural do capital", a recusa da crença de que estaríamos vivenciando mais uma crise episódica e pontual do sistema de produção capitalista, no início do século XXI.

Segundo Mészáros (2009), o que experimentamos nesse início de século tem raízes profundas no final dos anos de 1960, quando o sistema capitalista inicia uma nova fase. Essa nova etapa caracteriza-se, nas palavras do autor, por uma crise estrutural sociometabólica do capital, que afeta, sem distinção, todas as esferas de produção e reprodução da vida social.

De acordo com Maranhão (2020, p. 629), analisando a obra de Mészáros:

Depois de um longo período dominado pelas tradicionais crises cíclicas, que alternavam momentos de expansão e recessão, 0 sistema capitalista passa agora a atravessar uma crise endêmica,

\footnotetext{
3 "Nascido em 1930, na cidade de Budapeste, Hungria, István Mészáros tem desenvolvido importantes estudos que procuram resgatar a densidade e a radicalidade da crítica marxista ao sistema de produção e reprodução social baseado no capital" (MARANHÃO, 2020, p. 629).
} 
cumulativa, crônica e permanente, indicando a ativação dos limites estruturais absolutos do sistema sociometabólico do capital. Assim, a crise estrutural do capital tem aprofundado a histórica disjunção entre produção para as necessidades sociais e a autorreprodução do capital, ampliando suas características destrutivas e recolocando como imperativo vital para o futuro da humanidade a busca por uma alternativa ao sistema metabólico do capital.

Frente a essa crise, a resposta construída pelas elites dominantes dos países capitalistas ocidentais configurou-se no que chamamos de ofensiva neoliberal. Essa resposta foi buscar inspiração no passado, resgatando elementos do pensamento liberal.

O liberalismo clássico teve suas bases sócio-históricas desmontadas quando o capitalismo adentrou a era dos monopólios. A concepção do "livre mercado" transformou-se em retórica, uma vez que o movimento do capitalismo monopolista demandava um complexo de regulações e um Estado necessariamente intervencionista.

Apenas quando o Welfare State entrou em um ciclo crítico ocorreu o fenômeno denominado "revanche do mercado". Neste momento, a crise do Estado de bem-estar forneceu o combustível necessário para colocar em xeque as funções estatais como indutoras de crescimento econômico e promotoras de políticas sociais.

Porque é precisamente neste arco que está concentrada a essência do arsenal do neoliberalismo: uma argumentação teórica que restaura o mercado como instância mediadora societal elementar e insuperável e uma proposição política que repõe o Estado mínimo como única alternativa e forma para a democracia (NETTO, 1995, p. 77).

Assim, o Estado keynesiano 4 constituiu-se no maior alvo de ataques da ofensiva neoliberal. O ideário neoliberal se contrapôs ao conjunto dos direitos sociais

\footnotetext{
${ }^{4}$ Modelo de Estado vigente durante o Welfare State. Foi responsável por criar a ilusão da possibilidade de um compromisso entre capital e trabalho, mediado pelo Estado. Pautou-se no abandono do ideário socialista em troca de ganhos sociais. Mas, o Estado que se colocou como mediador, zelava pelos interesses do capital, cuidando de sua aceitação pelas entidades representativas dos trabalhadores.
} 
A conjuntura de uma pandemia e o que ainda está por vir - impactos e estratégias possíveis

conquistados pelos trabalhadores, às funções reguladoras macroscópicas do Estado, à cultura democrática, à busca pela redução das desigualdades econômicosociais.

Os sistemas de previdência e assistência social foram culpabilizados por exercerem "efeitos malignos" sobre a estrutura da sociedade, como o enfraquecimento dos alicerces familiares, a redução do incentivo para o trabalho, a diminuição da acumulação capitalista e a limitação da liberdade individual. Contudo, diante da miséria, os neoliberais admitem uma pequena intervenção do Estado: uma renda mínima destinada aos mais pauperizados, por exemplo.

No entanto, apesar da configuração teoricamente mínima que o Estado ganhou no neoliberalismo, na prática, suas responsabilidades não se realizam tão mínimas assim. O capitalismo neoliberal não pretende reduzir a intervenção do Estado, mas encontrar as condições favoráveis para direcioná-la segundo seus interesses particulares.

(...) nenhum grande burguês (e/ou seus executivos mais responsáveis) tem a menor ilusão acerca do abstencionismo estatal ou do mercado "livre"; nenhum deles imagina que a crise é uma invenção marxista; nenhum deles pretende erradicar mecanismos reguladores da economia. O que desejam e pretendem, em face da crise contemporânea da ordem do capital, é erradicar mecanismos reguladores que contenham qualquer componente democrática de controle do movimento do capital (NETTO, 1995, p. 81).

Por isso, a mesma burguesia monopolista foi a que patrocinou a ofensiva neoliberal. Ela possui a clareza da funcionalidade destes princípios num momento de crise do capital. Ela sabe que "a proposta do 'Estado mínimo' pode viabilizar o que foi bloqueado pelo desenvolvimento da democracia política - o Estado máximo para o capital" (NETTO, 1995, p. 81).

O neoliberalismo passou a ditar o programa que deveria ser implementado nos países capitalistas, contemplando reestruturação produtiva, privatização acelerada, enxugamento do Estado, políticas fiscal e monetária sintonizadas com os organismos mundiais de hegemonia do capital, como FMl e Bird, desmonte dos direitos sociais dos trabalhadores, combate ao sindicalismo de esquerda, 
propagação de um subjetivismo e de um individualismo exacerbados, entre outros (ANTUNES, 2002).

Este período concretizou uma ofensiva generalizada do capital e do Estado contra a classe trabalhadora e contra as condições vigentes durante a fase de apogeu de Estado de bem-estar social. Este novo quadro tinha um dos seus pólos centrais localizado no setor financeiro que ganhava autonomia dentro das complexas relações de liberação e mundialização dos capitais e do processo produtivo. Tudo isso num cenário caracterizado pela competição intercapitalista, pelo desenvolvimento tecnológico, pela devastação do meio ambiente e pela ação destrutiva, em escala mundial, contra a força de trabalho humana, que teve enormes contingentes precarizados ou mesmo relegados à margem do processo produtivo. Em meio a esta configuração ganhou destaque o desemprego estrutural e seus rebatimentos imediatos na forma de organização dos trabalhadores.

Desta forma podemos perceber que as crises sempre afetam tanto a materialidade da classe trabalhadora, ou seja, a sua forma de ser, quanto a sua esfera mais subjetiva, política e ideológica, ou seja, a arena dos valores e do ideário que pauta suas ações e práticas concretas.

Em um contexto mundial de tantas fragilidades e fraturas, uma pandemia, como a que estamos vivendo no ano de 2020 traz à tona, com toda a sua força, as nossas históricas mazelas. Portanto, estamos assistindo a um fenômeno de transformação da barbarização da vida social em banalidade cotidiana.

Nas palavras de Fontes (2020, p. 01):

Longe da falaciosa versão de que "vínhamos crescendo e o vírus pode atrapalhar" (...), a crise já estava em curso, e era anunciada pelos próprios economistas burgueses. Ora, se o capital promove crises quase permanentes, uma verdadeira "crise do capital" ocorre quando as massas irrompem na história e bloqueiam sua capacidade de recompor-se. Revolucionam a existência. Dão um basta a essa forma de economia e a esse modo de ser bárbaro e truculento.

Corroboramos com a análise da historiadora, ao afirmar que a atual crise em que estamos mergulhados não é fruto da pandemia. Ao contrário, essa pandemia apenas escancarou para todo o mundo o contexto de crise que já nos assolava, intensificando as suas refrações. Destacando que essa crise é vivenciada pelo 
A conjuntura de uma pandemia e o que ainda está por vir - impactos e estratégias possíveis

conjunto dos trabalhadores. O grande capital segue sua ofensiva, maximizando os lucros em detrimento da vida. Portanto, para colocar o capital em xeque, para provocar a sua ruptura se faz necessária a união da classe trabalhadora e o real enfrentamento desse modo de produção.

$E$, aqui estamos falando da verdadeira solidariedade de classe, não da falaciosa "união de todos", tão reverberada nesse contexto de crise sanitária. É muito comum, em momentos de crise aguda, como o que estamos atravessando, presenciarmos o chamamento à unidade. São comuns as máximas: "estamos todos no mesmo barco". Entretanto, em nosso entendimento, consideramos que estamos todos enfrentando a mesma tempestade - os mesmos temores e incertezas provocados por uma pandemia que afeta todas as sociedades, mas nos afeta de formas distintas. Por isso, poderíamos dizer que estamos todos enfrentando a mesma tempestade, mas utilizando embarcações bem diferentes. As elites burguesas ocupam luxuosos navios, transatlânticos ou até mesmo, submarinos mantendo asseguradas as suas planes condições de favorecimento em meio ao caos. Enquanto, a classe trabalhadora naufraga, submergindo em seus frágeis botes, canoas e jangadas, sem a mínima condição real de enfrentamento da situação de pandemia, nem garantia de sobrevivência.

Os dados não mentem e eles nos apontam que, no Brasil, "(...) por razões socioeconômicas e sociodemográficas, a doença matou mais pobres e pardos", segundo um levantamento exclusivo encomendado por ÉPOCA à consultoria Lagom Data, em que foram analisados dados de 54.488 vítimas da COVID-19, em nosso país.

Está explícito que os impactos dessa pandemia possuem efeitos diferentes e desiguais. $\mathrm{E}$ isso se dá pelo fato de a classe trabalhadora seguir muito mais exposta ao vírus, seja por suas precárias condições de moradia, seja por sua necessidade urgente e imediata de trabalhar.

As consequências e os impactos sociais dessa pandemia já são vislumbrados por nós nas próprias medidas apontadas pelos governos, privilegiando a todo 0 momento a lógica do capital: o aumento exponencial do desemprego, do 
subemprego, do trabalho intermitente e do processo de "uberização" 5 do trabalho. Esse cenário certamente se agravará pela quebra dos direitos trabalhistas e sociais, ainda sobreviventes, a expansão dos movimentos migrantes, o crescimento das populações de rua. Sem falar na elevação dos índices de adoecimento metal e suicídio, pois os períodos de crise, historicamente, nos revelam essas consequências.

Por tudo isso, somente o conjunto dos trabalhadores possui uma potencialidade transformadora capaz de estancar os avanços brutais do grande capital que tem nos conduzido, sem sombra de dúvidas, pelo caminho da barbárie.

\section{NO BRASIL: SHOW DE HORRORES CAPITANEADO PELO GOVERNO BOLSONARO}

No Brasil, além dos desdobramentos dessa crise sanitária, econômica e social mundial, ainda atravessamos uma crise política sem precedentes. Uma crise que, na realidade,

Já não se trata tão somente de uma crise política, que em parte decorreu e é paralela à crise econômica, mas de algo também com implicações jurídicas (na medida em que está em jogo o pacto democrático consagrado na Constituição de 1988), societais (uma vez que têm sido frequentes as fissuras nas relações interpessoais em parcelas da população) e culturais (posto que o jogo de forças tem levado a choques identitários, de valores e comportamentos) (ALMEIDA, 2019, p. 187).

O estopim da atual crise brasileira deu-se com o golpe de 2016 que afastou a ex-presidente Dilma Rousseff, encerrando o ciclo dos governos do Partido dos Trabalhadores (PT).

Dilma, mesmo tendo feito um governo (como fizeram os governos petistas desde 2003) predominantemente voltado para os interesses do grande capital e de seus sócios brasileiros e, a partir de 2015, tendo adotado um programa de governo muito semelhante ao que foi

\footnotetext{
${ }^{5}$ Termo cunhado por Ricardo Antunes em sua obra "O privilégio da servidão: o novo proletariado de serviços na era digital". São Paulo: Boitempo, 2018.
} 
apresentado (e derrotado) pelo candidato do PSDB em 2014, foi arrancada da presidência da República porque foi considerada incapaz de permanecer à frente dos interesses capitalistas que tanto serviu. Estes agora precisavam de um governo genuinamente burguês, capaz de não ceder o mínimo aos trabalhadores, de lhes retirar o pouco que conquistaram e de servir inteiramente, sem concessões, ao grande capital. O pacto de classes já não mais prestava (BRAZ, 2017, p. 87 e 88).

Na análise apresentada por Braz (2017, p. 93), "a derrota do PT respinga em toda a esquerda" brasileira. Isso acontece porque os setores ideológicos da classe dominante, rapidamente, se incumbiram de colocar todos os partidos, sindicatos e movimentos sociais de nosso país no "mesmo saco". Nesse sentido, a derrota do PT impactou diretamente a organização das forças de esquerda no nosso país, imediatamente após o golpe. Esse impacto se fez presente em meio ao senso comum da sociedade brasileira que passou a associar qualquer bandeira ou camiseta vermelha ao Partido dos Trabalhadores.

Por outro lado, o recuo democrático que vivenciamos a partir do golpe se aprofundou exigindo do campo da esquerda alguma unidade tática que não soube ser devidamente construída. Isto porque alguns segmentos da esquerda comemoraram a derrota do PT como se fosse uma vitória da classe trabalhadora. "Mais uma ilusão. Pior ainda: uma ilusão esquerdista que não enxerga que a conjuntura que se abriu com o impeachment expressa, antes de mais nada, uma vitória das forças à direita do PT" (BRAZ, 2017, p. 94). O golpe de Dilma significou o renascimento de fortes elementos do conservadorismo reacionário que estavam levemente adormecidos, em nosso país.

Por isso, a derrubada de Dilma e do PT significou muito mais do que um atentado à democracia. Representou o momento da retomada da hegemonia das elites dominantes no Brasil. O momento que inicia o estabelecimento de condições ideais para a reprodução dos interesses capitalistas, sem os entraves postos pela conciliação de classes (BRAZ, 2017).

No entanto, a tradicional agenda conservadora do PMDB e de seus apoiadores no Brasil (PSDB, DEM, PP, PR, PSB, PSD e outros) não conseguiu emplacar uma candidatura de peso no processo eleitoral de 2018. Diante da ameaça de ver o PT voltar ao poder, a saída da direita foi apoiar a candidatura de Bolsonaro. 
Com isso, o que assistimos foi a retomada de uma onda nazi-fascinsta pautada na intolerância, no genocídio e no extermínio das forças democráticas.

A intolerância de nossas classes dominantes não é um fenômeno conjuntural. Historicamente elas sempre foram muito avessas a avanços sociais, mesmo aqueles que não comprometem os seus interesses econômicos. A nossa formação social nos legou uma classe dominante preconceituosa, mesquinha, egoísta, antidemocrática e violenta (BRAZ, 2017, p. 101).

No cenário que se abre em tela temos: uma elite burguesa preconceituosa e intolerante; uma esquerda acuada e desorganizada; e uma massa de pessoas que se preocupam sazonalmente com a política, conforme acontecem os processos eleitorais ou os escândalos midiáticos.

$\mathrm{Na}$ análise de Almeida (2019, p. 190), "os canais de comunicação abertos na tv compõem o cenário doméstico para boa parte dessa população, principalmente as camadas mais pobres". A tv aberta ainda é, no Brasil, uma importante fonte de informação e de legitimação das narrativas políticas. Assim, esse canal produziu, nos últimos anos, uma "audiência da política" com o enfoque voltado para o tema do combate à corrupção.

Em um contexto de obrigatoriedade do voto, como o brasileiro, "essa audiência da política é convocada à participação no período eleitoral, quando é alcançada pelo horário eleitoral gratuito e, cada vez mais, pelas redes sociais digitais" (ALMEIDA, 2019, p. 190).

Merecem destaque nessa arena de interação política os efeitos crescentes da plataforma digital WhatsApp, por meio da qual circulam informações, fake news e memes em múltiplos grupos fechados que se sobrepõem às pequenas redes sociais: núcleo familiar, família extensa, grupos de trabalho, de amigos, de comunidades religiosas ou temporários com propósitos pontuais etc. (...) Porém, em 2018, a plataforma teve papel decisivo na construção da (i)legitimidade dos candidatos (ALMEIDA, 2019, p. 190).

O processo eleitoral de 2018 iniciou-se com grande multiplicidade de candidatos, mas terminou polarizado entre Fernando Haddad (PT) e Jair Bolsonaro (PSL). Nessa disputa, três processos foram decisivos para o resultado final: a 
enxurrada de fake news contra o candidato do PT; as pautas de defesa da "moral e dos costumes" assumidas por Jair Bolsonaro, agradando às forças cristãs do Congresso Nacional e solidificando sua base eleitoral evangélica; e a adesão das elites burguesas do nosso país à sua candidatura, especialmente, no segundo turno.

Desde então, vivemos, no Brasil, um show de horrores diário (permeado de declarações controversas e absurdas), capitaneado pelo governo Bolsonaro que, por trás dessa cortina de fumaça, conduz o Brasil a uma "democracia blindada" - nos termos de Demier (2017).

Nos estudos de Demier (2017), as "democracias blindadas" são compostas por governos que se dizem democráticos, mas se fecham cada vez mais às necessidades, às demandas e às reivindicações populares. Esses governos procuram blindar-se, tornando-se um ambiente fechado ao seu próprio grupo de interesse.

$\mathrm{Na}$ narrativa construída pelo autor, o entendimento da lógica do Estado burguês é peça-chave para o entendimento do Brasil, na atualidade. Segundo Demier (2017), as democracias blindadas, ao redor do mundo, são parte do projeto neoliberal de gestão burguesa dos Estados. Elas conformam o formato atual de garantia do contrarreformismo, assegurando que medidas extremamente impopulares sejam aprovadas e "vendidas" à população, como única maneira de solucionar problemas que o próprio capital gera continuamente - como as políticas que beneficiam o capital financeiro e especulativo internacional.

O Estado burguês, como vimos no primeiro tópico desse artigo, ora se abre um pouco mais para as demandas da classe trabalhadora (como ocorreu no período do Estado de bem-estar social), ora volta-se essencialmente para os interesses do capital (como no período atual de ofensiva neoliberal). Mas, o fato é que, de uma maneira ou de outra, o capital não vive sem o suporte do Estado. O Estado está sempre pronto para atender as necessidades do capital, inclusive nos momentos de convulsão, como ocorreu no ano de $2008^{6}$.

\footnotetext{
6 “'Observou-se no correr do ano de 2008 e seguinte que com a explosão das 'bolhas de Greenspan', a economia 'inabalável' padeceu, levando consigo uma enorme retração ao consumo, um avassalador desaparecimento do crédito no mercado e, consequentemente, uma explosão de desempregados não só naquele país, mas, também, no resto do planeta. Essa crise trouxe um questionamento, e talvez mais que isso, a afirmação de que apenas o discurso neoliberal não é suficiente para traçar as diretrizes necessárias ao enfrentamento desse momento
} 
Entretanto, justamente, quando estávamos vivendo um período de grande enxugamento do Estado, com cortes significativos nos gastos públicos, retração das políticas sociais, precarização dos serviços públicos e redução de direitos sociais e trabalhistas, nos assola um contexto de pandemia (global) que exige a intervenção estatal. E não a exige penas para o grande capital, mas para a massa da população que sofre, adoece e perde sua vida.

Então, o desmonte do Estado choca-se com a realidade posta pela pandemia que vai exigir investimentos em saúde pública, financiamento da ciência e tecnologia, crédito a setores micro-empresariais e redistribuição de renda para as parcelas mais empobrecidas da sociedade.

Frente a essa contradição, quando observamos o Brasil, em comparação a outros estados nacionais, as diferenças de condução desse processo são alarmantes. Em nosso país tivemos que nos submeter ao falso paradoxo criado pelo governo Bolsonaro: saúde x economia. Bolsonaro e seu núcleo de ministros criaram argumentos para acusar quem defende as medidas de distanciamento social de estarem contra o Brasil, contra o seu crescimento econômico. $O$ fato é que medidas de preservação da vida devem ser criadas em paralelo com políticas econômicas, que tenham o objetivo de evitar a dramática queda nas condições de vida da população durante a pandemia e a recuperação da agenda econômica no póspandemia.

No entanto, no Brasil, seguimos à deriva de um governo aparentemente sem comando. Sem as orientações unificadas, que seriam necessárias nesse momento, no dia 08 de agosto de 2020 ultrapassamos os 100 mil mortos pela COVID-19 (e esse número cresce a cada dia).

O que esse quadro nos revela? Uma falta de governo, de planejamento ou organização política? Novamente, se nos limitarmos a uma análise superficial dos fatos, pode parecer que sim. No entanto, essa é a real estratégia de um governo pautado na necropolítica ${ }^{7}$.

instável, restando mais uma vez ao Estado a incumbência de restaurar a 'normalidade' do mercado" (LUCENA et al, 2010, p. 162).

\footnotetext{
7 Termo cunhado pelo teórico camaronês Achille Mbembe que se refere às formas contemporâneas que subjugam a vida ao poder da morte.
} 
(...) propus a noção de necropolítica e necropoder para explicar as várias maneiras pelas quais, em nosso mundo contemporâneo, armas de fogo são implantadas no interesse da destruição máxima de pessoas e da criação de "mundos de morte", formas novas e únicas da existência social, nas quais vastas populações são submetidas a condições de vida que lhes conferem o status de "mortos-vivos" (MBEMBE, 2016, p. 146).

O governo Bolsonaro, seguindo a lógica do necropoder, mantém, desde o início dessa pandemia uma postura de negação da ciência, de minimização dos riscos do novo coronavírus e de disseminação de desinformação. "O caso mais significativo se deu após a Justiça ter proibido a veiculação da campanha 'O Brasil Não Pode Parar' pela SECOM (Secretaria de Comunicação Social da Presidência da República)" (KALIL; SANTINI, 2020, p. 02), uma clara demonstração do desprezo desse governo pelas vidas humanas perdidas. "A campanha, contrária ao isolamento social recomendado pela maioria dos governos no mundo e pelo Ministério da Saúde, criou um ambiente de controvérsia e contribuiu para a transformação da pandemia em 'infodemia'8" (KALIL; SANTINI, 2020, p. 07).

Nós ficamos estarrecidos frente as posturas do governo Bolsonaro porque somos dotados de humanidade. Temos medos, incertezas, sofremos um luto coletivo e nos solidarizamos com cada família que perde de forma estúpida e abrupta um ente querido. $\mathrm{E}$, em meio a esse cenário desolador gostaríamos de ter um governo que, minimamente, manifestasse o seu pesar, que se mostrasse sensível ao caos e nos dirigisse uma palavra de conforto.

Mas, como esperar isso de um governo genocida que aplaude a morte? A lógica do necropoder não é uma novidade no governo Bolsonaro. Ela já estava presente na sua campanha eleitoral pautada no preconceito e na intolerância. Sustentada na lógica nazi-fascista de extermínio do diferente. Jari Bolsonaro,

\footnotetext{
8 "A infodemia é caracterizada por uma quantidade e variedade excessiva de informações de diferente qualidade e credibilidade (algumas falsas, outras imprecisas, outras baseadas em evidências). A infodemia dificulta que as pessoas encontrem fontes e orientações confiáveis quando precisam, o que representa riscos para a saúde global" (KALIL; SANTINI, 2020, p. 05).
} 
presidente da república, é o mesmo sujeito que exaltou o comandante Ustra ${ }^{9}$ na votação do impeachment de Dilma, em 2016.

Portanto, não existe nada de novo no governo Bolsonaro que já não tivesse se anunciado antes. Deixar a população a sua própria sorte é máxima desse governo - e com sorte, na lógica de um comando genocida, o número de pretos e pobres mortos com essa pandemia continuará em ascensão. Segundo Goes, Ramos e Ferreira (2020, p. 02):

A pandemia do novo coronavírus tem sido um desafio para países que apresentam profundas desigualdades internas. E no Brasil as desigualdades têm raça, cor e etnia, pois é um país estruturado pelo racismo, que permanece com as suas raízes fincadas no sistema escravocrata. É um processo histórico que ao longo do tempo tem determinado os lugares sociais das pessoas de acordo com a raça ou etnia.

Por isso, no Brasil, a população negra certamente vem sofrendo, de maneira mais severa, os impactos dessa pandemia. Corroboram para isso a histórica ausência de garantia de direitos e a maior prevalência de doenças crônicas e negligenciadas entre a população negra. Processos resultantes do descaso social e econômico ao qual ela está exposta e ao menor acesso aos serviços de saúde (GOES, RAMOS E FERREIRA, 2020).

Para além das condições de saúde da população negra, no Brasil, precisamos levar em conta "a sua distribuição no espaço geográfico das grandes metrópoles nacionais, que são marcadas fortemente pela segregação residencial racial, onde negras e negros residem às margens, nas franjas das cidades" (GOES, RAMOS E FERREIRA, 2020).

A segregação cria condições adversas à saúde, pois, historicamente, os locais onde reside a maioria das pessoas negras são precários, com moradias inadequadas em relação às condições estruturais, sem acesso a serviços básicos de saneamento, água potável, equipamentos de saúde, (...) (GOES, RAMOS E FERREIRA, 2020, p. 04).

\footnotetext{
${ }^{9}$ Em 2008, por decisão em primeira instância do juiz Gustavo Santini Teodoro, da $23^{\text {a }}$ Vara Cível de São Paulo, o coronel Ustra tornou-se o primeiro oficial condenado em ação declaratória por sequestro e tortura, mais de trinta anos depois de fatos ocorridos durante a ditadura militar (1964-1985).
} 
Outro fator que o racismo condiciona, em nosso país, é a adoção de medidas preventivas para a COVID-19. O distanciamento social, a principal medida preventiva elencada pela Organização Mundial de Saúde (WHO, 2020), não pode ser usufruído da mesma forma por todas em pessoas. No Brasil, as "negras e negros representam a maioria dos trabalhadores informais, de serviço doméstico, comercial, da alimentação, transporte, armazenamento e correio, que se mantiveram ativos, mesmo durante a pandemia" (GOES, RAMOS E FERREIRA, 2020, p. 04). A higienização das mãos, outra medida preventiva para a COVID-19, recomendada pela WHO (2020), está, muitas vezes, distante da realidade da população negra, "visto que, muitas moradias, em diversas regiões do país, não têm acesso a água e saneamento básico, (...) (GOES, RAMOS E FERREIRA, 2020, p. 04).

A pandemia desnuda o quanto o Brasil é um país desigual e pouco avançou na superação do racismo. No entanto, para conter a expansão da pandemia no país e dar o próximo passo, será preciso, em primeiro lugar, enfrentar o racismo e as desigualdades, porque, além de tudo, a população negra representa mais da metade da população brasileira (GOES, RAMOS E FERREIRA, 2020, p. 04).

Por todos esses elementos, o contexto da pandemia, no Brasil, é gravíssimo. $E$, ao invés, de contarmos com seu enfrentamento efetivo, o governo Bolsonaro minimiza a seriedade da pandemia e contribui para a disseminação de informações fraudulentas e sem respaldo científico (LIMA et. al., 2020). "Ele busca protagonizar a defesa da 'flexibilização' do isolamento social, apesar de estudos científicos dizerem o contrário" (LIMA et. al., 2020, p, 12).

Estamos submersos em um contexto que parece estar caracterizado pelo "declínio da verdade" ou "obscurantismo da razão", que representa o enfraquecimento das análises concretas dos fenômenos sociais em prol da "adoção de perspectivas relativistas e subjetivas extremas, com a glorificação da opinião acima do conhecimento (incluindo o especializado), das emoções acima dos fatos" (LIMA et. al., 2020, p, 15).

Diante de tantos desafios postos e outros ainda por vir, quais seriam as possíveis estratégias de enfrentamento a serem construídas pela esquerda do nosso 
A conjuntura de uma pandemia e o que ainda está por vir - impactos e estratégias possíveis

país? Não temos as respostas, mas estamos dispostos a refletir sobre esse tema com você, em nosso próximo tópico.

\section{POSSIBILIDADES TÁTICAS E ESTRATÉGICAS PARA A DEFESA DA VIDA}

Jair Messias Bolsonaro ${ }^{10}$ foi eleito presidente da república, em de 2018, utilizando uma estratégia da campanha eleitoral capaz de congregar uma multiplicidade de eleitores. Esses, em sua maioria, se definem como conservadores e/ou de direita. A principal estratégia de comunicação eleitoral de Bolsonaro procurou disseminar diferentes informações para variados perfis de potenciais apoiadores (KALIL, 2018). Essa estratégia "conseguiu construir uma imagem de Bolsonaro capaz de assumir múltiplas formas, de acordo com as diferentes aspirações de suas bases" (SCHUTTE; FONSECA; CARNEIRO, 2019, p. 102). Entretanto, dentro dessa multiplicidade, a base eleitoral de Bolsonaro caracteriza-se, especialmente, por fazer a defesa e se autointitular "cidadão de bem"11.

Um dos principais elementos que constituem a figura do "cidadão do bem" é o discurso contra a corrupção, amplamente polissêmico, (...). Esse discurso assume também a existência de uma "desordem" dos costumes e valores que coloca em risco uma suposta ordem familiar, amplamente ligada à prática religiosa e a condutas privadas e morais relacionadas à sexualidade (SCHUTTE; FONSECA; CARNEIRO, 2019, p. 103).

Esse discurso que faz a defesa da anticorrupção apresenta, ainda, um terceiro significado, diretamente associado a uma suposta confusão entre "direitos e privilégios", que se desenrola nas críticas feitas aos programas sociais e de cotas (KALIL, 2018). À esse discurso anticorrupção, se somam as defesas anticomunistas, formando um amplo leque que aglutina "o temor a uma noção de esquerda política

\footnotetext{
${ }^{10}$ Jair Messias Bolsonaro é capitão reformado do exército brasileiro, foi deputado por seis mandatos e é o atual presidente do Brasil, eleito em 2018.

11 “Uma designação que se refere àquele que possui condutas e práticas 'corretas' no âmbito da vida privada e que, na vida pública, considera-se e comporta-se de maneira distinta à dos chamados 'corruptos' e 'bandidos"” (SCHUTTE; FONSECA; CARNEIRO, 2019, p. 103).
} 
pré-associada ao petismo, ao bolivarianismo, ao 'marxismo cultural' e ao autoritarismo" (SCHUTTE; FONSECA; CARNEIRO, 2019, p. 103).

Existe, ainda, um posicionamento claramente contrário à "ideologia de gênero", "que reúne discursos hostis à comunidade LGBT com acusações de pedofilia e críticas à educação social nas escolas" (SCHUTTE; FONSECA; CARNEIRO, 2019, p. 103).

Destaca-se, também, a tônica de um discurso que clama por "ordem" e "segurança", respaldado no medo que é fruto da ineficiência da segurança pública. Esse discurso se apresenta com caráter extremamente punitivista, fundamentando propostas de redução da maioridade penal e bandeiras como "bandido bom é bandido morto" (KALIL, 2018).

\begin{abstract}
Dentro do espectro do "cidadão de bem" há, portanto, um matiz que comporta diferentes eleitores de Bolsonaro. Há os que defendem uma redução drástica do Estado a partir do "anticomunismo" e do "combate à corrupção". Existem os que priorizam a preservação da estrutura familiar tradicional com base na religião diante da ameaça da "ideologia de gênero" e da "desordem de costumes e valores". Assim como há também os que, frente a um cenário que entendem como de "corrupção generalizada", buscam soluções a partir da ressignificação da história ou do espelhamento em outros países vistos como exemplos a serem seguidos (SCHUTTE; FONSECA; CARNEIRO, 2019, p. 103).
\end{abstract}

Dentro dessa base heterogênea que elegeu Bolsonaro em 2018, o núcleo duro conforma o que denominamos de "extrema direita". De acordo com Chaú (2016), o crescimento desses grupos radicais de direita, no nosso país, foi impulsionado pelas manifestações de junho de 2013. Na época esse movimento foi pouco percebido e menos ainda analisado. Mas, ao longo dos anos, demonstrou uma crescente aceitação de pautas ultraconservadoras, pela opinião pública, e a ampliação da sua representatividade institucional na política brasileira.

A partir do ano de 2015, podemos perceber, com nitidez, o crescimento do clamor pelo retorno do regime ditatorial militar no Brasil; maior presença de grupos de extrema-direita, como Tradição, Família e Propriedade (TFP); e, nas instâncias representativas, o fortalecimento da bancada parlamentar dos 3Bs (Boi, Bala, Bíblia) - "vinculadas, respectivamente, às demandas dos setores agropecuaristas, das 
instituições militares e de segurança pública e dos cristãos conservadores" (MORAIS, 2019, p. 155).

Contudo, se múltipla e heterogênea é a base que elegeu Bolsonaro, também é diversa sua base governista. O núcleo duro, composto pelo próprio presidente e alguns aliados próximos, compõe a chamada "ala olavista" - inspirados na filosofia política de Olavo de Carvalho ${ }^{12}$.

O projeto político "olavista" é essencialmente conservador e consiste em combater o globalismo. O globalismo, se expressa, segundo esse grupo, por meio de três grandes projetos contemporâneos:

(...) o islamismo, que seria o maior projeto e a maior ameaça para a Europa; o comunismo, a "ditadura do partido único", representado pela Rússia e pela China; e "o positivismo da sociedade administrada, a tecnocracia neoliberal do liberalismo anticristão", representado pelo expresidente norte-americano Barack Obama, Emmanuel Macron e outras elites ocidentais (SCHUTTE; FONSECA; CARNEIRO, 2019, p. 104 e 105).

Por isso, os autores acima mencionados, destacam que é equivocado pensar que o discurso da "ala olavista" seria despido de racionalidade, como se fosse um "ato cínico, conduzido aleatoriamente, ou mero fruto de devaneios alheios à realidade" (SCHUTTE; FONSECA; CARNEIRO, 2019, p. 99). Ao contrário, as ações do governo Bolsonaro são dotadas de um propósito muito bem determinado e, em certa medida, atendem os anseios e as aspirações ideológicas e culturais de parte importante do seu eleitorado. Como, por exemplo, os posicionamentos consoantes com o governo Trump e com o nacionalismo antiglobalista, que insiste na negação dos problemas ambientais e na reprovação dos Direitos Humanos (SCHUTTE; FONSECA; CARNEIRO, 2019).

Contudo, essa forma "olavista" de governar não agrada toda a sua base de governo. A forma como Bolsonaro tem conduzido a política nacional e internacional,

\footnotetext{
12 "O pensamento de Olavo de Carvalho acerca da política nacional possui duas premissas fundamentais: a população brasileira é acentuadamente conservadora e a democracia é um sistema em que há uma oscilação pendular entre projetos políticos diferentes. Olavo de Carvalho advoga que os Estados Unidos são o verdadeiro exemplo de democracia moderna, uma vez que apresenta oscilação pendular entre esquerda progressista e direita conservadora" (SCHUTTE; FONSECA; CARNEIRO, 2019, p. 104).
} 
no Brasil, muitas vezes tem sido criticada e encontra opositores diretamente ligados aos interesses das elites econômicas dentro e fora do país.

Por isso, seu governo não conseguiu abrir mão da realização dos "conchavos", tão duramente criticados em período eleitoral, ditos como sendo práticas de uma "velha política". Foi assim que o governo conseguiu estabelecer as alianças necessárias com o "centrão" para aprovar pautas de seu interesse, indo na contramão das necessidades do conjunto dos trabalhadores brasileiros.

As Forças Armadas também ganham destaque no governo Bolsonaro. Nos últimos anos esse segmento foi lentamente se deslocando para o centro do poder. Os militares foram ocupando espaços no sistema político, conquistando a aprovação da opinião pública, já muito afetada pela insegurança causada pela criminalidade (ALMEIDA, 2019).

Além de Bolsonaro e seu vice, Hamilton Mourão, muitos militares e policiais também foram eleitos para os legislativos estaduais e para o federal, nas últimas eleições. Assim, "o espectro militar materializou-se por meio do processo democrático e não por intervenção, a ponto de a questão política candente hoje ser a sutil e fundamental distinção entre um governo militar e um governo com militares na ordem democrática" (ALMEIDA, 2019, p. 193 e 194).

Diante desse amálgama de forças em articulação para garantir a manutenção de Bolsonaro no poder, o enfrentamento desse governo pautado na morte, precisa, necessariamente, ser feito pelos setores da esquerda do nosso país. Está nas nossas mãos a mobilização, a organização, a realização de alianças que tenham como objetivo maior a defesa da vida.

No entanto, a esquerda brasileira, em seu sentido amplo, vem sofrendo, nos últimos anos, uma profunda estigmatização ao ser tomada de forma genérica como "petista". São colocados no "mesmo saco" todas as forças políticas de oposição, inclusive aquelas que se distanciaram da experiência de um governo pautado na conciliação de classes (IASI, 2020).

O golpe sofrido pelo PT, em 2016, representou uma derrota concreta para a esquerda do nosso país, abrindo espaço para a ofensiva desmedida do grande capital contra a classe trabalhadora. Assim, a resistência do conjunto dos trabalhadores, que se fez presente na cena política através do aumento do número 
de greves e das tentativas de greves gerais, "fica prejudicada pela falta de unidade nos enfrentamentos decisivos e em torno de um programa comum" (IASI, 2020, p. 02).

\begin{abstract}
Enquanto a classe dominante disputa intensamente o sentido das mudanças que devem se impor, mas se une em torno das medidas imediatas, a classe trabalhadora parece demonstrar uma incapacidade de se unir quanto aos rumos a seguir no médio prazo e isso acaba por impedir sua necessária unidade no enfrentamento das medidas impostas pelas classes dominantes (IASI, 2020, p. 02).
\end{abstract}

Estão aí colocados os nossos maiores desafios. A esquerda brasileira precisa, com urgência, ser capaz de se apresentar como uma alternativa à sociedade, diferenciando-se das propostas apresentadas pelos partidos de centro. O PT, por exemplo, "tem todo o direito de apresentar uma posição de centro no espectro político brasileiro, tem o protagonismo e a experiência para isso, tem, ainda, o direito de tentar apresentar tal posição como se fosse de centro-esquerda" (IASI, 2020, p. 04). Cabe ao bloco da esquerda (partidos, sindicatos, movimentos sociais e populares) o papel de revelar à sociedade quais são as diferenças entre esses projetos.

Nesse sentido, precisamos explicitar nossas defesas em favor da vida, demarcando em que medida nos diferenciamos tanto da direita e da extrema direita, quanto do centro. Nesse interim faz-se necessário refutar a aliança com setores dominantes, pois a estratégia da conciliação de classes já demonstrou o seu fracasso com a ruína dos governos do PT (IASI, 2020).

É certo que não devemos desconsiderar a necessidade das alianças táticas, imprescindíveis nesse momento. Para o enfrentamento de um governo genocida, como o de Bolsonaro, precisamos construir amplas articulações táticas com todos aqueles que estejam clamando "fora Bolsonaro e Mourão". Entretanto, a longo prazo, faz-se necessária a construção de estratégias que busquem a construção de alianças pautadas nos mesmos princípios, alicerçadas em uma mesma concepção de sociedade.

A principal tarefa da esquerda, portanto, deve ser a defesa de uma sociedade que seja capaz de assegurar "o livre desenvolvimento de cada indivíduo como 
condição para o livre desenvolvimento de todos os indivíduos" (NETTO; BRAZ, 2010, p. 246).

A luta pela vida, tão imperativa hoje, nesses tempos de pandemia, não pode se reduzir à defesa das condições vitais, necessárias à nossa sobrevivência. A vida precisa ser buscada e alcançada em sua plenitude. Defender a vida, em última instância, significa lutar para romper com a lógica de uma sociedade que mata cotidianamente milhares de pessoas, alijando suas possibilidades de existência.

\section{CONSIDERAÇÕES FINAIS}

Marx e Engels (2008, p. 09 e 10) abrem o texto que ficou mundialmente conhecido como o "manifesto comunista" dizendo que: "um espectro ronda a Europa: o espectro do comunismo. (...) Já é tempo de os comunistas exporem abertamente sua visão de mundo, seus objetivos e suas tendências, contrapondo assim um manifesto do próprio partido à lenda do espectro do comunismo".

Nos parece que, em pleno século XXI, essa indicação continua relevante. Frente ao "espectro contemporâneo do comunismo", diante de tudo o que se propaga enquanto ideologia comunista, precisamos perder o medo de nos dizer comunistas e explicar para as pessoas o que, verdadeiramente, é o comunismo.

Compreendemos o momento histórico no qual estamos vivendo como um período de regressão nas lutas sociais, de postura defensiva das organizações e movimentos de esquerda. Mas, até quando vamos permanecer acuados nos bastidores? Precisamos encontrar maneiras de recuperar o nosso protagonismo subindo novamente aos palcos.

Segundo Netto e Braz (2010), vivemos, nesse primeiro quarto de século XXI, um "novo mundo", cujas mudanças, em relação ao século passado, são praticamente impossíveis de se esboçar de maneira resumida. Mas, entre suas principais tendências está a "ofensiva do capital sobre o trabalho e, por isso mesmo, significa uma regressão social quase inimaginável" (NETTO, BRAZ, 2010, p. 237) há cinquenta anos atrás.

De acordo com os autores, 
O saldo da ofensiva do capital, apreciado brevemente, explicita as três questões que aparecem como próprias do "mundo novo": "o crescente alargamento da distância entre o mundo rico e o pobre (e [...], dentro do mundo rico, entre os seus ricos e seus pobres); a ascensão do racismo e da xenofobia; e a crise ecológica do globo, que nos afetará a todos" (HOBSBAWM in BLACKBURN, org., 1992, p. 104). Nenhuma dessas questões pode ser resolvida nos marcos do capitalismo contemporâneo (NETTO; BRAZ, 2010, p. 238).

No Brasil, assistimos, em meio ao avanço da pandemia COVID-19, o crescimento vertiginoso desses três aspectos: o país chega a ter, aproximadamente, treze milhões de brasileiros desempregados no primeiro trimestre de $2020^{13}$; o aumento nos casos explícitos de racismo, por todo o país são estarrecedores ${ }^{14}$; e o meio ambiente nunca foi tão atacado pelo próprio governo como no momento atual $^{15}$.

Diante desse cenário de barbárie crescente, não podemos nos calar. Precisamos ser a voz que ecoa a defesa da vida e dos direitos humanos. Não podemos nos tornar insensíveis, naturalizando e banalizando a mortes das milhares de vidas ceifadas em meio a essa crise humanitária. É tempo de reação. É tempo de buscar em nossos pares a força necessária para a luta e não ter medo de dizer, como Ernesto Che Guevara: "se você é capaz de tremer de indignação a cada vez que se comete uma injustiça no mundo, então somos companheiros.

Em um estudo publicado em setembro de 2019, elaborado pelo Instituto Datafolha, identificou-se que o núcleo duro de apoiadores de Bolsonaro denominado pela pesquisa de "bolsonaristas heavy" - consiste em apenas $12 \%$ da população. Em seguida, encontram-se os entusiastas médios, que correspondem a $22 \%$ dos brasileiros. Estes votaram em Bolsonaro, porém não aprovam ou não confiam plenamente nas palavras do presidente (JANONI; PAULINO, 2019).

\footnotetext{
${ }^{13}$ Segundo dados do IBGE, em 30/04/2020.

${ }^{14}$ Como exemplo dos casos de João Pedro (18/05/2020), Miguel (02/06/2020), Matheus Fernandes e Matheus Pires (07/08/2020), entre tantos outros.

${ }^{15}$ Durante a reunião ministerial do dia 22 de abril, o ministro do Meio Ambiente, Ricardo Salles, alertou os ministros sobre o
que considerava ser uma oportunidade trazida pela pandemia da Covid-19: para ele, o governo deveria aproveitar o momento
em que o foco da sociedade e da mídia está voltada para o novo coronavírus para "passar a boiada" e mudar regras que
podem ser questionadas na Justiça, conforme vídeo divulgado pelo ministro do Supremo Tribunal Federal (STF) Celso de
Mello.
} 
Esses dados nos revelam que o grupo de apoiadores que segue fiel à logica da morte capitaneada pelo governo Bolsonaro é, hoje, minoritária. Precisamos expandir a nossa defesa em prol de "um mundo onde sejamos socialmente iguais, humanamente diferentes e totalmente livres", como sonhava Rosa Luxemburgo.

Vivemos, inegavelmente, um momento agudo de crise planetária. Mas, nas palavras de Gramsci: "a crise consiste precisamente no fato de que o velho está morrendo e o novo ainda não pode nascer. Nesse interregno, uma grande variedade de sintomas mórbidos aparece". Assim tem sido o momento presente, um amálgama de vida e morte; um emaranhado de atitudes fúnebres em meio a lampejos de resistência. Pois que sejamos a resistência!

Existe um elemento central, do campo marxista que precisa urgentemente ser resgatado: o elemento revolucionário. Nós precisamos construir um mundo novo, de fato. O próprio "capitalismo contemporâneo, ao exacerbar todas as contradições do modo de produção capitalista, criou também a condição necessária para a sua substituição por uma outra organização societária, capaz de efetivamente instaurar um - sem aspas - mundo novo" (NETTO, BRAZ, 2010, p. 238). Sejamos, então, construtores desse novo mundo!

\section{REFERÊNCIAS BIBLIOGRÁFICAS}

ALMEIDA, Ronaldo de. Bolsonaro presidente: conservadorismo, evangelismo e a crise brasileira. Novos Estudos - CEBRAP, v. 38, n. 01. São Paulo: jan./abr. 2019, p. 185-213.

ANTUNES, Ricardo. Os Sentidos do Trabalho: Ensaio sobre a afirmação e a negação do trabalho. 6.ed. São Paulo: Biotempo, 2002.

BRAZ, Marcelo. O golpe nas ilusões democráticas e a ascensão do conservadorismo reacionário. Revista Serviço Social e Sociedade, n. 128. São Paulo: jan./abr. 2017, p. 85-103.

CHAUÍ, M. 2016. Sociedade brasileira: violência e autoritarismo por todos os lados - depoimento. Entrevista concedida a Juvenal Savian Filho e Laís Modelli. Revista Cult. 2016. Disponível em: www.revistacult.uol.com.br/home/2016/02/sociedadebrasileira-violencia-e-autoritarismo-portodos-os-lados. Acesso em: 12/08/2020.

DEMIER, Felipe. Depois do golpe: a dialética da democracia blindada no Brasil. Rio de Janeiro: Mauad X, 2017. 
FONTES, Virgínia. Coronavírus e a crise do capital. Disponível em: https://adufs. org.br/conteudo/1883/coronavirus-e-a-crise-do-capital-entrevista-com-virginia-fontes. Acesso em: 10/08/2020.

GOES, Emanuelle F.; RAMOS, Dandara O.; FERREIRA, Andrea J. F. Desigualdades raciais em saúde e a pandemia da Covid-19. Trabalho, Educação e Saúde, Rio de Janeiro, v. 18, n. 3, 2020, e00278110. DOI: 10.1590/1981-7746sol00278.

IASI, Mauro Luís. A Esfinge que nos devora: os desafios da esquerda brasileira. Disponível em: https://marxismo21.org/wp-content/uploads/2017/05/Mauro-lasi-Aesfinge-que-nos-devora-as-perspectivas-na-esquerda-no-Brasil-1.pdf. Acesso em: $13 / 08 / 2020$.

JANONI, Alessandro; PAULINO, Mauro. Núcleo duro de apoio a Bolsonaro é de $12 \%$ da população, aponta Datafolha. Folha de São Paulo, 2019. Disponível em: https://www1.folha.uol.com.br/poder/2019/09/nucleo-duro-de-apoio-a-bolsonaro-ede-12-da-populacao-aponta-datafolha.shtml. Acesso em: 14/08/2020.

KALIL, Isabela. Quem são e no que acreditam os eleitores de Jair Bolsonaro. Fundação Escola de Sociologia e Política de São Paulo. Outubro, 2018.

KALIL, I.; SANTINI, R. M. Coronavírus, Pandemia, Infodemia e Política. Relatório de pesquisa. Divulgado em 01 de abril de 2020. 21p. São Paulo / Rio de Janeiro: FESPSP/UFRJ. Disponível em: https://www.fespsp.org.br/store/file source/FESPSP/ Documentos/Coronavirus-e-infodemia.pdf. Acesso em: 12/08/2020.

LIMA, C. R. M. et. al. Emergência de saúde pública global por pandemia de COVID-19: desinformação, assimetria de informações e validação discursiva. Disponível em: file:///C:/Users/lugpp/Downloads/410-Preprint\%20Text-508-3-1020200509.pdf. Acesso em: 12/08/2020.

LUCENA, Glauber et. al. Intervenção estatal nas crises econômicas: breve análise judírico-econômica dos instrumentos governamentais brasileiros para a indução de sua economia em 2008/2009. Revista Direito e Desenvolvimento, a. 1, n. 2, jul./dez. 2010, p. 161-173.

MARX, Karl; ENGELS, Friedrich. Manifesto do partido comunista. São Paulo: Expressão Popular, 2008.

MBEMBE, Achille. Necropolítica. Arte e ensaios. Revista do PPGAV/EBA/UFRJ, n. 32, dez. 2016, p. 123-151.

MÉSZÁROS, István. A crise estrutural do capital. São Paulo: Boitempo, 2009.

MORAIS, A. R. A. O discurso político da extrema direita brasileira na atualidade. Cadernos de Linguagem e Sociedade, 2019, p. 152-172. 
NETTO, José Paulo; BRAZ, Marcelo. Economia política: uma introdução crítica. 6.ed. São Paulo: Cortez, 2010.

NETTO, José Paulo. Crise do Socialismo e Ofensiva Neoliberal. 2.ed. São Paulo: Cortez, 1995.

SCHUTTE, G. R.; FONSECA, B. C. D.; CARNEIRO, G. S. Jogo de dois níveis voltado ao eleitorado: uma análise da política externa bolsonarista. Revista Conjuntura Global, v. 8, n. 2, 2019, p. 97-116.

WORLD HEALTH ORGANIZATION (WHO). Coronavirus disease (Covid-19) advice for the public. Disponível em: https://www.who.int/emergencies/diseases/novel-coronavirus-2019/advice-forpublic. Acesso em: 12/08/2020. 